\title{
Data report: analysis of shear wave anisotropy in upper oceanic crust, ODP/IODP Hole 1256D' ${ }^{1}$
}

\author{
N.V. Zakharova ${ }^{2}$ and D.S. Goldberg ${ }^{2}$
}

\section{Chapter contents}

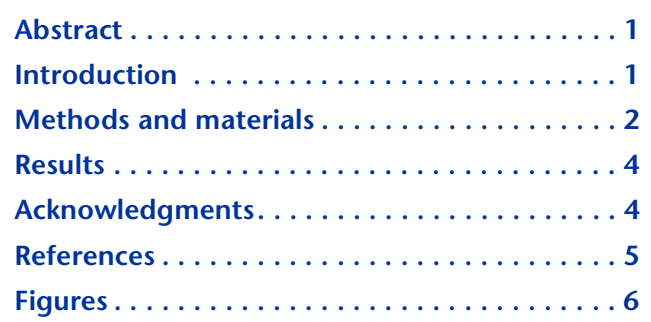

\section{Abstract}

Integrated Ocean Drilling Program Hole 1256D is one of the few deep holes that penetrate through the upper oceanic crust and offers a unique chance to study its anisotropic properties as a function of depth. In this report, we present the results of anisotropy analysis using downhole sonic logging data acquired in Hole $1256 \mathrm{D}$. The analysis is based on the detection of shear wave splitting in azimuthally anisotropic formations; however, poor borehole conditions, high levels of noise, and insufficient tool rotation presented significant challenges in this analysis. Anisotropy could be reliably evaluated only over a few select depth intervals, and they suggest very low shear wave anisotropy, within a range of $0 \%-1 \%$. In particular, the deepest logged section within the sheeted dike interval is characterized by good borehole conditions and high coherence of shear wave fields, but shear wave velocity appears to be isotropic and/or characterized by weak anisotropy below the detection limit of the Dipole Sonic Imager used to acquire the data.

\section{Introduction}

Understanding in situ properties of oceanic crust has been an important goal of marine geology and geophysics. Seismic studies, in particular, have provided crucial insights into structure and intrinsic properties of oceanic crust (e.g., Carbotte et al., 2008; Harding et al., 1989; Tolstoy et al., 2008; Vera and Diebold, 1994). Although seismic velocity profiles in oceanic crust are well understood (e.g., Spudich and Orcutt, 1980; White et al., 1992), the anisotropy of seismic waves has received less attention. Observations of seismic anisotropy may provide useful insights into intrinsic properties of crust and mantle, such as preferred orientation of mineral fabric and structural features, and the distribution of in situ stress and strain (e.g., Russo and Silver, 1994; Savage, 1999; Schoenberg and Sayers, 1995; Silver and Chan, 1988). In the upper crust, seismic anisotropy is usually attributed to microfracturing and large-scale fractures (Rasolofosaon et al., 2000; Stephen, 1985), whereas in the low crust and mantle, it is related to the crystal preferred orientation or fabric of anisotropic minerals (Ko and Jung, 2015; Rasolofosaon et al., 2000).

Several active-source seismic studies of $P$ and $S$ body waves have reported $1 \%$ to $5 \%$ azimuthal anisotropy in the upper crust, at- 
tributed to near-vertical water-filled cracks in Layer 2 (Dunn and Toomey, 2001; Stephen, 1985; White and Whitmarsh, 1984). No apparent spreading-rate dependence of the anisotropy magnitude was observed, but it was reported to decrease with depth due to gradual crack closing in the upper $2 \mathrm{~km}$ of the crust (Dunn and Toomey, 2001). Observed anisotropy direction varied from roughly ridge-parallel (Dunn and Toomey, 2001) to ridge-oblique by $20^{\circ}-$ $60^{\circ}$ (Stephen, 1985; White and Whitmarsh, 1984). Due to limited spatial resolution, these seismic studies could constrain anisotropy directions only within a $10^{\circ}$ azimuthal range, at best. An alternative technique with potentially higher azimuthal resolution is provided by dipole sonic logging tools, which record cross-dipole shear wave fields around boreholes using orthogonal source and receiver pairs (Esmersoy et al., 1994; Iturrino et al., 2005). These data are usually acquired continuously with depth and can be analyzed for the presence of shear wave splitting in anisotropic formations. Dipole logging tools have been used routinely in the Ocean Drilling Program (ODP) and the Integrated Ocean Drilling Program (IODP) in recent years and allow for anisotropy measurements of oceanic crust of different ages when recorded at different geographic sites and under different tectonic settings.

Borehole studies of shear wave anisotropy in oceanic crust to date are sparse. Iturrino et al. (2005) analyzed sonic logs from Deep Sea Drilling Project Hole 395A near the Kane Fracture Zone on the Mid-Atlantic Ridge and ODP Hole 735B near the Atlantis Fracture Zone on the Southwest Indian Ridge (slow to intermediate crustal spreading rates). The results revealed a complex pattern of varying degree of anisotropy with depth from $1 \%$ to $15 \%$, with the mean direction of the fast shear wave velocity $\left(V_{S}\right)$ oriented oblique to (Hole 395A) and perpendicular to (Hole 735B) nearby ridge segments, but varying widely about the mean $V_{S}$ at different depths. The authors attributed this result to a combination of intrinsic effects from fracturing, foliation, and porosity heterogeneity, as well as to stresses potentially inducing changes in the local borehole environment. Resolving the sources of anisotropy in the oceanic crust at both locations proved to be challenging. However, those sites are located in the vicinity of an active fracture zone, which may considerably complicate both the stress field and the tectonic setting near the site. In this study, we analyze shear wave anisotropy in another deep hole, ODP/IODP Hole 1256D, located on the undeformed flank of the East Pacific Rise.

Hole $1256 \mathrm{D}$ is one of the few deep holes that penetrate through the upper oceanic crust and offers a unique opportunity to study anisotropy as a function of crustal depth. The site is located on the Cocos plate on the eastern flank of the East Pacific Rise (Fig. F1), which formed $\sim 15 \mathrm{~m} . \mathrm{y}$. ago at a fast spreading rate $(>200 \mathrm{~mm} / \mathrm{y}$ full rate) (see the "Expedition 335 summary" chapter [Expedition 335 Scientists, 2012]). Drilled during four expeditions (ODP Leg 206 and IODP Expeditions 309, 312, and 335) to a total depth of 1522 meters below seafloor (msbf), Hole $1256 \mathrm{D}$ intersects roughly $250 \mathrm{~m}$ of sediment, $700 \mathrm{~m}$ of lava, $350 \mathrm{~m}$ of sheeted dikes, and then encounters gabbro at $\sim 1410$ mbsf (Fig. F2). Sonic logging data were recorded during three of the four expeditions, but they did not record data over the full depth interval due to obstructions in sections of the hole during operations. In this report, we present anisotropy analysis and results over the longest logged interval of Hole 1256D using the Dipole Sonic Shear Imager (DSI; 300-1215 mbsf; acquired during Expedition 309), which recorded the highest data quality and allows for the best estimations of shear wave anisotropy.

\section{Methods and materials Principles of sonic anisotropy analysis}

Sonic anisotropy analysis of downhole logging data utilizes the physical phenomenon of shear wave splitting. When a shear wave propagates through anisotropic media, it is polarized, or "split," into two directions aligned with the fast and slow axis of the formation. In the case of aligned fractures and/or other structural features, the fast direction is along the strike of these features; for stress-induced anisotropy, the fast shear aligns with the direction of the far-field maximum principal stress (Ellis and Singer, 2007; Sinha and Kostek, 1996). Thus, by measuring the polarization direction and the difference in the arrival times of the fast and slow shear waves, it is possible to infer the direction and degree of formation anisotropy. For most downhole logging measurements, sonic waves travel along the borehole axis and are polarized in various azimuthal orientations with respect to the axis (Fig. F3). They are, therefore, most sensitive to the azimuthal variability of formation properties in the plane perpendicular to the borehole axis. In a vertical borehole, this means that the highest sensitivity to azimuthal variations occurs in the horizontal plane (e.g., produced by subvertical features and/or unequal horizontal stresses). Such media are classified as transversely isotropic with a horizontal axis of symmetry, or TI-H.

The DSI that was deployed in Hole 1256D utilizes directional sources and receivers, allowing for oriented recording of polarized shear waves in an anisotropic 
formation (Ellis and Singer, 2007). Four waveforms are analyzed simultaneously at each depth from two source-receiver pairs (two in-line and two cross-line). In order to determine the fast and slow directions for an arbitrary azimuthal orientation of the tool in the borehole, the four wave fields are numerically rotated into the principal planes using the Alford rotation procedure (Alford, 1986). In this procedure, the following parameters characterize the measured anisotropy and are simultaneously derived: the fast shear azimuth (FSH), cross-energy, and traveltime anisotropy. The numerically rotated fast and shear wave forms are processed to determine fast-shear and slow-shear slownesses (inverse of $V_{\mathrm{S}}$ ) and to compute shear slowness anisotropy. The details of the processing algorithms can be found in Ellis and Singer (2007), Sinha and Kostek (1996), and Sinha et al. (1994). The next section summarizes the main anisotropy parameters needed to understand the outcomes of the sonic anisotropy analysis conducted in Hole 1256D.

\section{Key anisotropy parameters}

In total, three parameters quantifying the amount of anisotropy, slowness anisotropy, traveltime anisotropy, and energy anisotropy, are computed during these processing steps:

- Slowness anisotropy is the difference between the fast and slow slowness calculated on rotated waveforms and normalized to the average slowness. It is the main indicator of the magnitude of shear wave anisotropy (in percent of average $V_{S}$ ).

- Traveltime anisotropy is the arrival-time difference between the rotated fast and shear waves averaged across the receiver array and normalized by the average arrival time to compute a percentage difference. This serves as a secondary indicator of anisotropy and requires good borehole conditions to be meaningful.

- Energy anisotropy is a spectral parameter that quantifies the amount of energy in the cross-component waveforms and is computed as a percentage of total energy in all four rotated wave field components. Two related parameters are also computed: the minimum and the maximum cross-energy. The minimum cross-energy, when close to zero, indicates that the Alford rotation procedure was successful. The maximum crossenergy is proportional to the degree of anisotropy and should be significantly greater than the minimum cross-energy if, in fact, shear wave splitting is observed.

Sonic anisotropy analysis is most reliable when the following measurement conditions are satisfied:
- The tool is consistently rotating while logging the borehole, thus providing full azimuthal coverage, and the FSH does not track the tool orientation. Tool rotation is recorded during data acquisition with the Pad 1 azimuth (P1AZ). Typically, tools rotate during logging, but they may become "locked" at a particular azimuth due to irregularities in the well bore. Tool azimuth is an important quality control parameter to make sure that calculated FSH is independent of the tool orientation in the borehole.

- Borehole conditions are good and borehole diameter is not significantly enlarged in any orientation around the hole. Hole quality can be checked using a caliper log, which measures borehole diameter in two orthogonal directions.

- The minimum cross-energy is small or close to zero and the maximum cross-energy is significantly greater than the minimum cross-energy. This indicates that shear wave splitting has been measured and the Alford rotation procedure was successful. Slow and fast velocity components can then be reliably separated.

Under these conditions, both slowness and traveltime anisotropy estimates should be similar and allow for a reliable magnitude estimate of anisotropy in the formation. The FSH indicates the strike of the formation anisotropy, the intrinsic features that are potentially responsible for causing it, and/or the orientation of the maximum horizontal stress in the formation.

\section{Frequency-slowness analysis (dispersion plots)}

An additional and powerful tool for detecting the presence of shear wave anisotropy and understanding its nature is the analysis of shear wave dispersion. Shear waves in boreholes are produced by flexural waves created by directional sources, locally deforming the borehole perpendicular to its axis. These flexural waves are inherently dispersive (i.e., their velocity depends on frequency; Sinha et al., 1994). In an anisotropic formation, curves of the slow and fast shear wave velocity separate as a function of frequency, and the pattern of this separation on a dispersion plot may allow for stress-induced and intrinsic sources of anisotropy to be distinguished (Fig. F4). For intrinsic anisotropy, for example, the fast shear wave travels parallel to the strike of formation features and the slow shear wave travels perpendicularly to them. The fast and slow shear wave dispersion curves are nonintersecting over the entire frequency band. The fast-shear direction determined form the rotated waveform indicates the strike of anisotropic features in the formation. For stress-induced anisotropy, when anisotropy is due to 
stress imbalance in the borehole cross-sectional plane, the fast shear aligns with the direction of the far-field stress and the fast and slow shear wave dispersion curves cross over at an intermediate frequency (Fig. F4; Sinha et al., 2000). For an isotropic formation, the fast and slow shear slownesses are identical and overlap in the dispersion plot.

\section{Results}

Figure F5 summarizes the results of shear wave anisotropy analysis for Hole 1256D. The tool azimuth profile indicates that the tool was not rotating consistently inside the borehole over most of the logged interval. At least three depth intervals, however, exhibit a consistent tool rotation ( $\sim 400-500$ and $625-$ 760 mbsf and deeper than 980 mbsf). Caliper logs show large washouts (borehole enlargements) throughout the hole, but the caliper is nearly in gauge at 490-520, 600-625, 700-780, and 850-910 mbsf and deeper than 1080 mbsf. With poor borehole conditions, obtaining reliable anisotropy parameters is not feasible. Waveform processing was unable to achieve consistent near-zero values for the minimum cross-energy, so fast and slow components of the shear wave field are poorly distinguished. The best results from the processing show several intervals where this parameter is close to zero: $\sim 500$, $\sim 710, \sim 820$, and $\sim 990$ mbsf and deeper than 1080 mbsf (Fig. F5). However, even in these zones, the maximum cross-energy is not very high, indicating low energy and little shear splitting. Consequently, there is almost no difference between the fast and slow shear wave slownesses at these depths, suggesting that either the formation is isotropic in a horizontal plane or that anisotropy could not be detected or both (the slowness resolution of the DSI is $2 \mu \mathrm{s} / \mathrm{ft}$ [i.e., $1 \%-2 \%$ ] of the measured slowness range). The computed slowness anisotropy is $1 \%$ of average $V_{S}$ (Fig. F5) and is quite variable. The computed time anisotropy is much greater, up to $10 \%$ in certain intervals, but these values are likely overestimated because of the poor borehole conditions. As expected, there is no dominant orientation of the fast $V_{\mathrm{S}}$ azimuth in isotropic intervals (Fig. F5). Fast shear azimuth is variable and averages $90^{\circ}$, the median value of the range of all possible orientations $\left(0^{\circ}-180^{\circ}\right)$; therefore, it does not help to differentiate a fast $V_{S}$ azimuth. Hole conditions toward the bottom of the logged interval are consistent, however, and the computation of anisotropy parameters is reliable. Over this interval, our sonic anisotropy analysis suggests that the lower oceanic crust is isotropic in a horizontal plane.
Figure F6 illustrates the sonic waveform data and the anisotropy computation over the lower interval of Hole 1256D (1140-1190 mbsf). The interval is characterized by a relatively large difference between the minimum and maximum cross-energy values (Fig. F5) and relatively high coherence of the fast and slow components (Fig. F6). The fast and shear slowness curves can be reliably determined and are nearly identical. The estimated anisotropy is close to zero, which suggests that the formation is isotropic in the plane perpendicular to the borehole (i.e., in the horizontal plane). This interval corresponds to the sheeted dike section of the oceanic crust (Fig. F2); given the vertically oriented morphologies in this formation that are similar in all azimuthal directions, it is anticipated to be isotropic in a horizontal plane unless a strong stress imbalance or preferred crack orientation is present. Low estimates of anisotropy, however, are also computed at shallower depths in intervals where the borehole conditions are good and sonic logging waveforms have high coherence (i.e., 310-340, 470-530, and 970-1005 mbsf and deeper than $1060 \mathrm{mbsf}$ ). Within all of these intervals, dispersion curves show overlapping curves for fast and shear slownesses at all frequencies (Fig. F7). From these consistent analyses of sonic anisotropy over select intervals in Hole 1256D, our results clearly suggest that at sonic logging frequencies these sections of upper oceanic crust are characterized by isotropic shear wave velocity in a horizontal plane.

In summary, poor borehole conditions and insufficient tool rotation presented significant challenges for sonic anisotropy analysis in Hole 1256D. Anisotropy parameters could be reliably determined from the logging data over limited depth intervals. They clearly suggest that the upper oceanic crust is nearly isotropic in a horizontal plane, with $V_{\mathrm{S}}$ anisotropy estimates between $0 \%-1 \%$ of the average horizontal $V_{S}$, and/or that weak shear-wave anisotropy is below the detection limit of the DSI used to acquire the data.

\section{Acknowledgments}

We thank the crew, technical staff, and scientists aboard the R/V JOIDES Resolution during ODP/IODP Expeditions 309, 312, and 335, which enabled shear wave logging data acquisition in Hole 1256D. The U.S. Science Support Program (USSSP) sponsored by the U.S. National Science Foundation (NSF) provided funding for this study. We also thank Schlumberger for help with data processing. 


\section{References}

Alford, R.M., 1986. Shear data in the presence of azimuthal anisotropy: Dilley, Texas. SEG Technical Program Expanded Abstracts 1986, 476-479. http://dx.doi.org/ 10.1190/1.1893036

Arroyo Franco, J.L., Mercado Ortiz, M.A., De, G.S., Renlie, L., and Williams, S., 2006. Sonic investigations in and around the borehole. Oilfield Review, 18(1):14-33.

Carbotte, S.M., Nedimovic, M.R., Canales, J.P., Kent, G.M., Harding, A.J., and Marjanovic, M., 2008. Variable crustal structure along the Juan de Fuca Ridge: influence of on-axis hot spots and absolute plate motions. Geochemistry, Geophysics, Geosystems, 9(8):Q08001. http:// dx.doi.org/10.1029/2007GC001922

Dunn, R.A., and Toomey, D.R., 2001. Crack-induced seismic anisotropy in the oceanic crust across the East Pacific Rise $\left(9^{\circ} 30^{\prime} \mathrm{N}\right)$. Earth and Planetary Science Letters, 189(1-2):9-17. http://dx.doi.org/10.1016/S0012821X(01)00353-3

Ellis, D.V., and Singer, J.M., 2007. Well Logging for Earth Scientists (2nd ed.): New York (Elsevier).

Esmersoy, C., Koster, K., Williams, M., Boyd, A., and Kane, M., 1994. Dipole shear anisotropy logging. SEG Technical Program Expanded Abstracts 1994, 1139-1142. http:// dx.doi.org/10.1190/1.1822720

Expedition 309/312 Scientists, 2006. Site 1256. In Teagle, D.A.H., Alt, J.C., Umino, S., Miyashita, S., Banerjee, N.R., Wilson, D.S., and the Expedition 309/312 Scientists. Proceedings of the Integrated Ocean Drilling Program, 309/312: Washington, DC (Integrated Ocean Drilling Program Management International, Inc.). http:// dx.doi.org/10.2204/iodp.proc.309312.103.2006

Expedition 335 Scientists, 2012. Expedition 335 summary. In Teagle, D.A.H., Ildefonse, B., Blum, P., and the Expedition 335 Scientists, Proceedings of the Integrated Ocean Drilling Program, 335: Tokyo (Integrated Ocean Drilling Program Management International, Inc.). http:// dx.doi.org/10.2204/iodp.proc.335.101.2012

Harding, A.J., Orcutt, J.A., Kappus, M.E., Vera, E.E., Mutter, J.C., Buhl, P., Detrick, R.S., and Brocher, T.M., 1989. Structure of young oceanic crust at $13^{\circ} \mathrm{N}$ on the East Pacific Rise from expanding spread profiles. Journal of Geophysical Research: Solid Earth, 94(B9):12163-12196. http://dx.doi.org/10.1029/JB094iB09p12163

Iturrino, G.J., Goldberg, D., Glassman, H., Patterson, D., Sun, Y.-F., Guerin, G., and Haggas, S., 2005. Shear-wave anisotropy from dipole shear logs in oceanic crustal environments. Geological Society Special Publication, 240:117-131. http://dx.doi.org/10.1144/ GSL.SP.2005.240.01.10

Ko, B., and Jung, H., 2015. Crystal preferred orientation of an amphibole experimentally deformed by simple shear. Nature Communications, 6:6586. http:// dx.doi.org/10.1038/ncomms7586

Rasolofosaon, P.N.J., Rabbel, W., Siegesmund, S., and Vollbrecht, A., 2000. Characterization of crack distribution: fabric analysis versus ultrasonic inversion. Geophysical Journal International, 141(2):413-424. http:// dx.doi.org/10.1046/j.1365-246x.2000.00093.x
Russo, R.M., and Silver, P.G., 1994. Trench-parallel flow beneath the Nazca plate from seismic anisotropy. Science, 263(5150):1105-1111. http://dx.doi.org/ 10.1126/science.263.5150.1105

Savage, M.K., 1999. Seismic anisotropy and mantle deformation: what have we learned from shear wave splitting? Reviews of Geophysics, 37(1):65-106. http:// dx.doi.org/10.1029/98RG02075

Schoenberg, M., and Sayers, C.M., 1995. Seismic anisotropy of fractured rock. Geophysics, 60(1):204-211. http://dx.doi.org/10.1190/1.1443748

Silver, P.G., and Chan, W.W., 1988. Implications for continental structure and evolution from seismic anisotropy. Nature, 335(6185):34-39. http://dx.doi.org/10.1038/ $335034 a 0$

Sinha, B.K., Kane, M.R., and Frignet, B., 2000. Dipole dispersion crossover and sonic logs in a limestone reservoir. Geophysics, 65(2):390-407. http://dx.doi.org/ 10.1190/1.1444734

Sinha, B.K., and Kostek, S., 1996. Stress-induced azimuthal anisotropy in borehole flexural waves. Geophysics, 61(6):1899-1907. http://dx.doi.org/10.1190/ 1.1444105

Sinha, B.K., Norris, A.N., and Chang, S.-K., 1994. Borehole flexural modes in anisotropic formations. Geophysics, 59(7):1037-1052. http://dx.doi.org/10.1190/ 1.1443660

Spudich, P., and Orcutt, J., 1980. A new look at the seismic velocity structure of the oceanic crust. Reviews Of Geophysics, 18(3):627-645. http://dx.doi.org/10.1029/ RG018i003p00627

Stephen, R.A., 1985. Seismic anisotropy in the upper oceanic crust. Journal of Geophysical Research: Solid Earth, 90(B13):11383-11396. http://dx.doi.org/10.1029/ JB090iB13p11383

Tolstoy, M., Waldhauser, F., Bohnenstiehl, D.R., Weekly, R.T., and Kim, W.-Y., 2008. Seismic identification of along-axis hydrothermal flow on the East Pacific Rise. Nature, 451(7175):181-184. http://dx.doi.org/ 10.1038/nature06424

Vera, E.E., and Diebold, J.B., 1994. Seismic imaging of oceanic Layer $2 \mathrm{~A}$ between $9^{\circ} 30^{\prime} \mathrm{N}$ and $10^{\circ} \mathrm{N}$ on the East Pacific Rise from two-ship wide-aperture profiles. Journal of Geophysical Research: Solid Earth, 99(B2):30313041. http://dx.doi.org/10.1029/93JB02107

White, R.S., McKenzie, D., and O’Nions, R.K., 1992. Oceanic crustal thickness from seismic measurements and rare earth element inversions. Journal of Geophysical Research: Solid Earth, 97(B13):19683-19715. http:// dx.doi.org/10.1029/92JB01749

White, R.S., and Whitmarsh, R.B., 1984. An investigation of seismic anisotropy due to cracks in the upper oceanic crust at $45^{\circ} \mathrm{N}$, Mid-Atlantic Ridge. Geophysical Journal of the Royal Astronomical Society, 79(2):439-467. http:// dx.doi.org/10.1111/j.1365-246X.1984.tb02234.x

Initial receipt: 26 October 2014

Acceptance: 14 September 2015

Publication: 2 November 2015

MS 335-202 
Figure F1. Age map of the Cocos plate and adjacent regions of the Pacific and Nazca plates based on magnetic anomalies (see the "Expedition 335 summary" chapter [Expedition 335 Scientists, 2012]). Select DSDP and ODP sites that reached basement are indicated by circles; FZ = fracture zone.

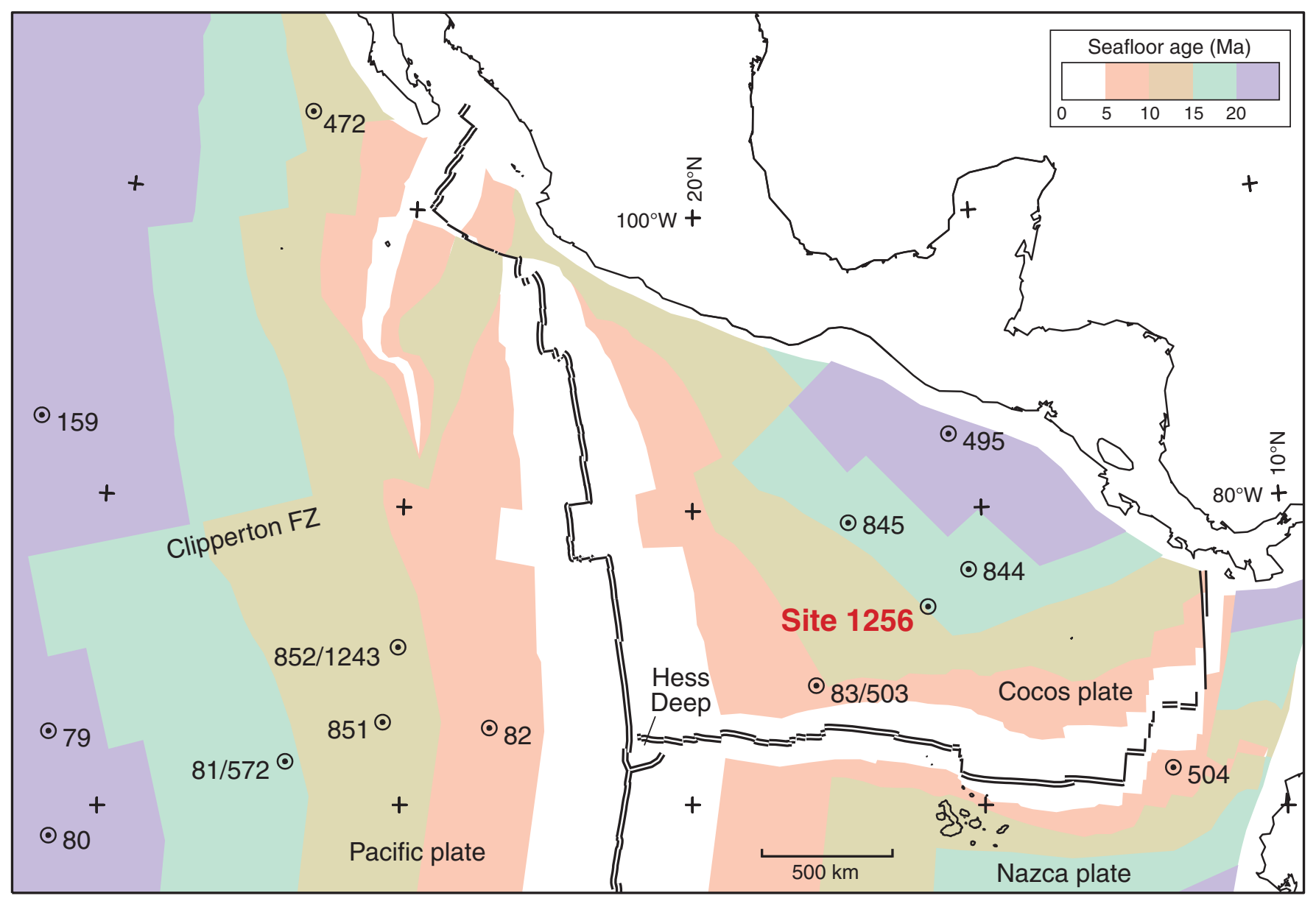


Figure F2. Sonic tool deployments and stratigraphic column in Hole 1256D showing the major and minor lithologic divisions of the upper oceanic crust, after Expedition 335 Scientists (2012) and Expedition 309/312 Scientists (2006). Sonic tool data were analyzed over the depth interval highlighted in red.

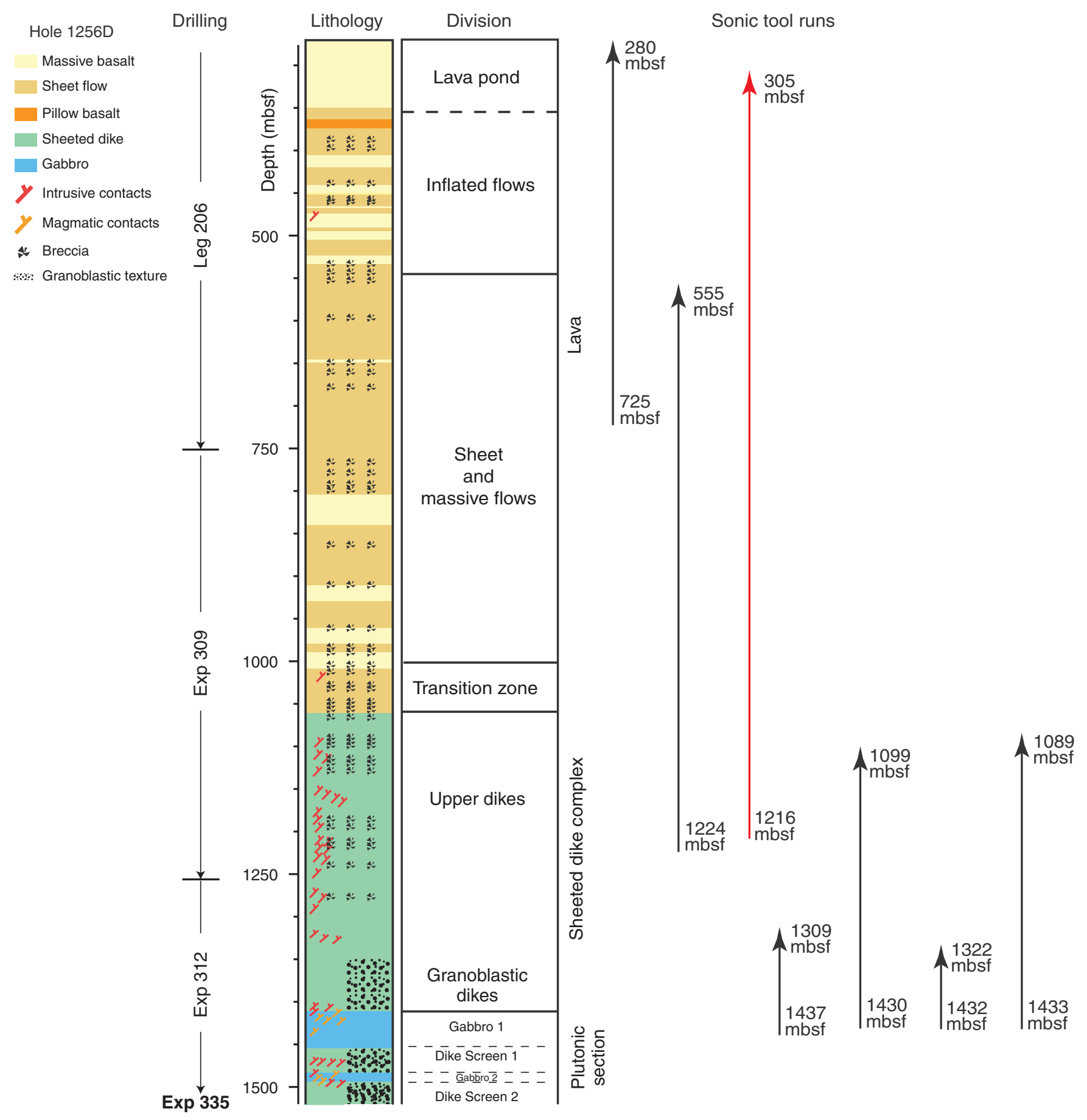


Figure F3. Schematic diagram of shear wave spitting in downhole logging caused by azimuthal alignment of subvertical cracks. Dipole sonic wave fields are analyzed for azimuthal orientation and degree of anisotropy. After Ellis and Singer (2007).

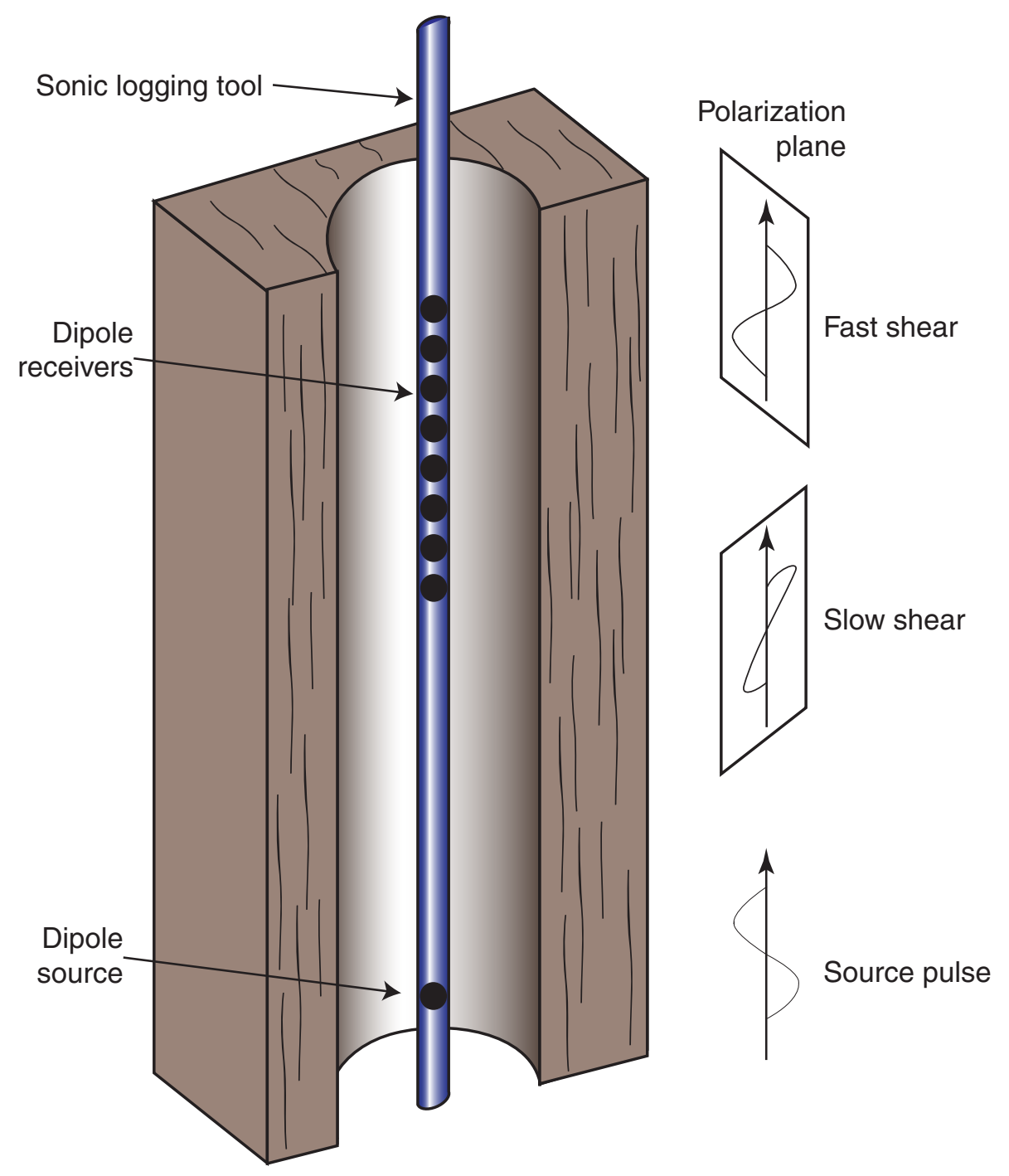


Figure F4. Schematic cross-dipole dispersion curves illustrating isotropic and anisotropic formations. In homogeneous isotropic medium (left panel), observed dispersion curves for the orthogonal fast and slow shear wave components (red and blue curves) are identical and match modeled flexural wave dispersion (black circles). In homogeneous anisotropic medium (middle panel), such as one with intrinsic anisotropy created by cracks or other features, the fast and slow dispersion curves are offset, but parallel. In inhomogeneous anisotropic medium (right panel), such as created by stress-induced anisotropy, the two observed dispersion curves crossover at an intermediate frequency (Arroyo Franco et al., 2006).

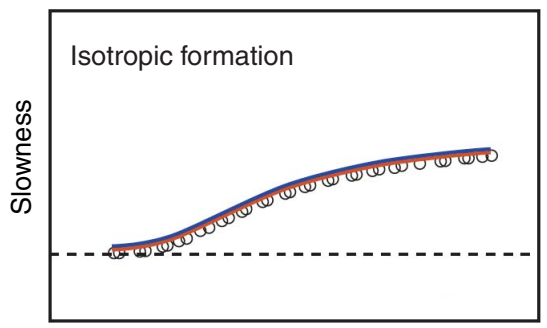

Frequency

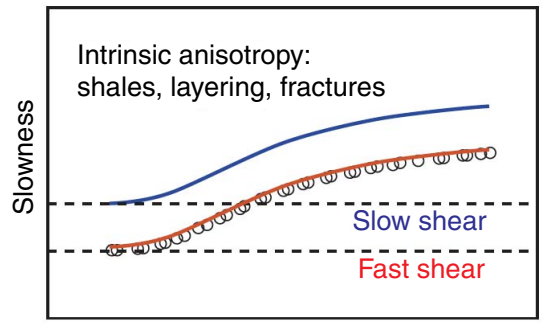

Frequency

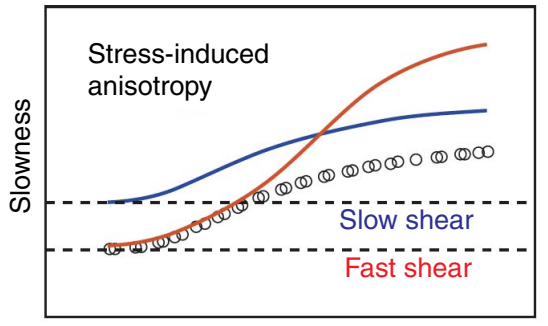

Frequency 
Figure F5. Sonic anisotropy analysis results, Hole 1256D. Tool azimuth is as indicated by the orientation of Pad 1 , minimum and maximum cross-energy is after Alford rotation, and fast-shear and slow-shear slowness is determined from the rotated wave fields. For fast-shear azimuth, smoothed data is the $10 \mathrm{~m}$ running average.

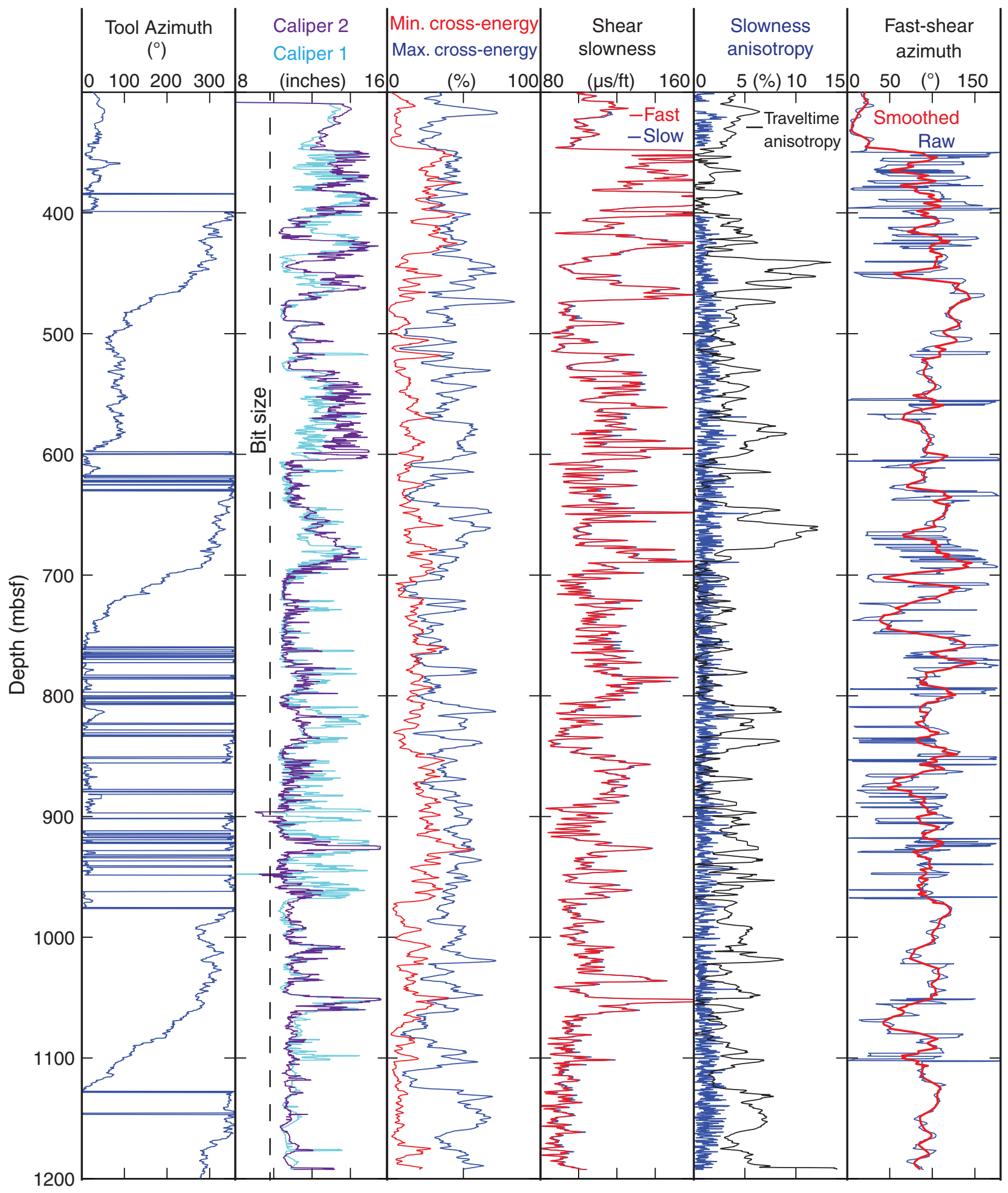


Figure F6. An example of shear wave field with relatively high coherency in the bottom part of Hole1256D (sheeted dike section). The first track on the left shows borehole diameter recorded by two orthogonal calipers. Rotated fast and slow shear wave fields are shown in the middle, along with corresponding coherency plots of shear-wave arrivals. Shear slowness: black = compressional slownesses. Slow and fast slownesses are very similar, thus, suggesting isotropic formation. Fast-shear azimuth (red; determined by Alford rotation): gray = uncertainty.

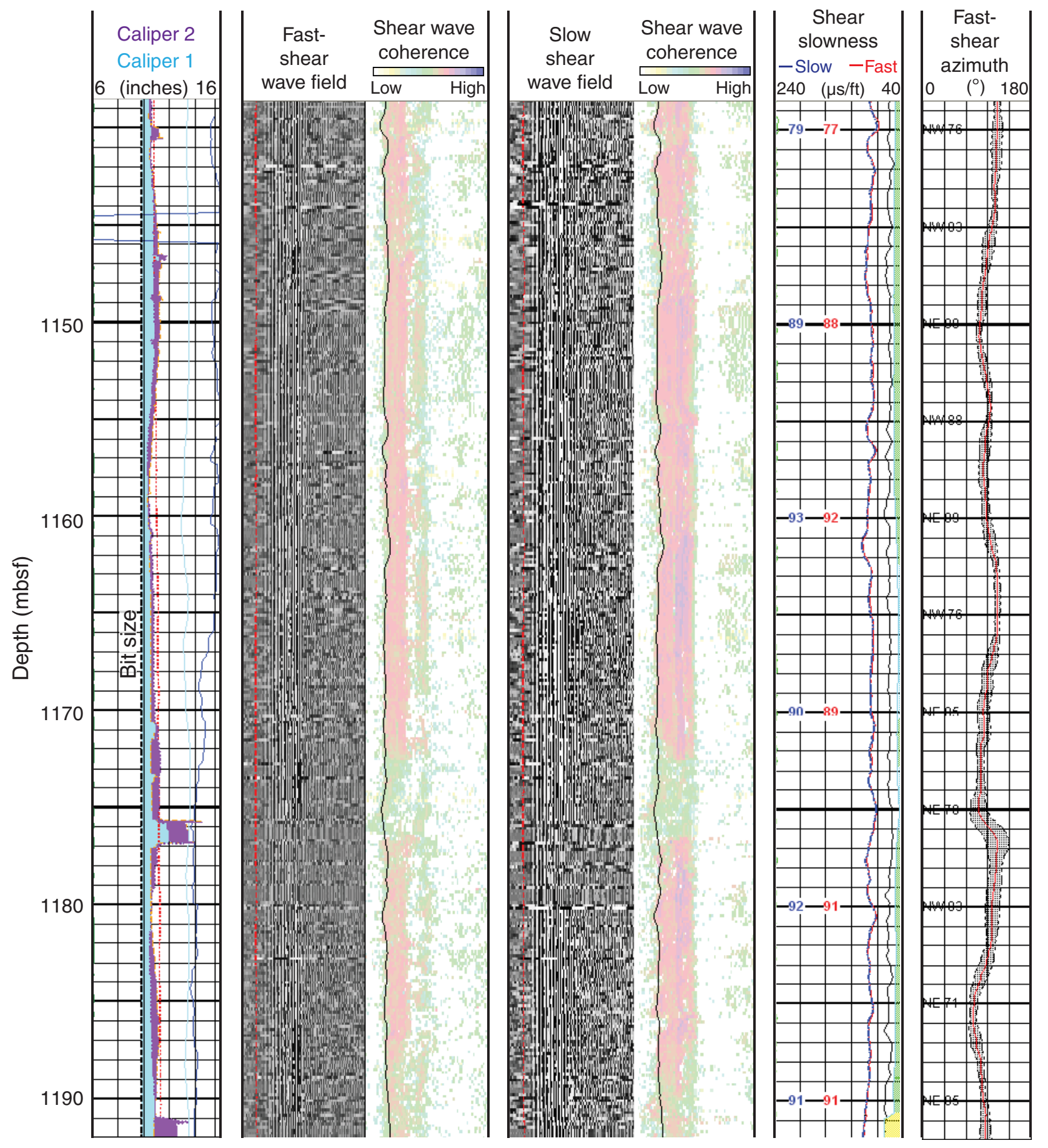


Figure F7. Example of flexural wave dispersion plot at $480 \mathrm{mbsf}$, Hole 1256D. Green and red dashed lines indicate compressional wave and shear-wave slownesses, respectively. Dispersion curves for dipole flexural wave computed are from rotated slow and fast shear wave fields. Green circles correspond to Stoneley wave slowness, which provides an upper limit for flexural wave slowness (Ellis and Singer, 2007). Overlapping fast and slow dispersion curves are indicative of isotropic formation.

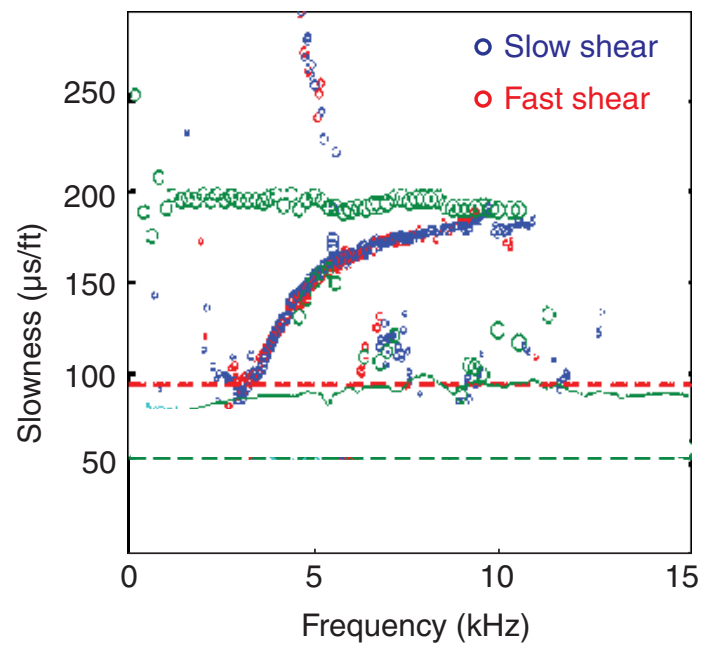

